\title{
A variação da vibrante em início de sílaba no português falado na antiga região de colonização italiana do Rio Grande do Sul: em busca de um padrão regional
}

\author{
Trill and tap alternation at the beginning of the syllable in the spoken Portuguese in the \\ former region of Italian colonization of Rio Grande do Sul: in search of a regional standard
}

Priscila Silvano Azeredo Velho ${ }^{1}$

RESUMO: 0 presente artigo analisa resultados de alguns estudos sobre a variação da vibrante realizados em municípios da RCI-RS. Consideramos os resultados de nosso estudo (AZEREDO 2012) no português brasileiro de Flores da Cunha/RS em comparação aos resultados obtidos em outros dois municípios vizinhos, Antônio Prado (CORRÊA 2016) e Caxias do Sul (BOVO 2004), com o propósito de verificar a possibilidade de definir a RCI-RS como uma comunidade de fala. Através do exame dos resultados de nossa análise observamos tanto convergências quanto divergências dialetais no que tange aos fatores condicionadores do processo variável. Também foi possível observar que as variáveis sociais desempenham forte condicionamento sobre a regra variável de realização do tepe em lugar de vibrante. Podemos confirmar apenas parcialmente a hipótese de a RCI-RS ser uma comunidade de fala relevante para a realização da vibrante simples em lugar de múltipla. Nosso estudo mostrou que, a despeito de muitas similaridades e da italianidade compartilhada, as realidades locais, coincidentes com os limites municipais, precisam ser contempladas na análise desse processo variável em específico.

PALAVRas CHAVE: Variação da vibrante; RCI-RS; Comunidade de Fala.

ABSTRACT: This article analyzes the results of some studies on the vibrant variation performed in cities of RCI-RS. We consider the results of our study (Azeredo 2012) in Brazilian Portuguese of Flores da Cunha/RS compared to the results obtained in two other neighboring cities, Antonio Prado (Correa 2016) and Caxias do Sul (BOVO 2004), in order to verify the ability to set the RCI-RS as a speech community. By examining the results of our analysis we observe both convergences and dialectal differences with respect to the conditioning factors of the process variable. It was also observed that the social variables play strong conditioning on the variable rule of realization of tap where a trill is expected . We can confirm only partially the hypothesis of the RCI-RS be an important speaking community for the realization of tap in trill places. Our study showed that, despite many similarities and shared Italianity, local realities coincide with municipal boundaries, need to be addressed in the analysis of this variable process specific.

KEYwoRDS: Trill and tap alternation; RCI-RS; Speaking Community. 


\section{Introdução}

onforme Monaretto (1997), "Os diferentes tipos de $r$, dependentes do dialeto e do contexto linguístico, são considerados variantes da vibrante". Entende-se por vibrante, do ponto de vista fonético, o som que ocorre por pequenas oclusões produzidas pelo dorso ou ponta da língua batendo repetidas vezes contra a arcada dentária superior, contra os alvéolos ou contra o véu palatino através da ação da corrente de ar. Ao invés de produzir oclusões, a língua também pode não fechar totalmente a passagem de ar, fazendo com que a vibração desapareça e dê lugar para o som fricativo ou aspirado, o que, segundo Monaretto (1997), é muito comum nas línguas. A essas modalidades de articulações dá-se o nome de $r$-forte, também chamado de vibrante múltipla, verificadas em vocábulos do português como roda, corrida, por exemplo.

Já ao som de $r$ produzido com uma só batida da língua junto aos alvéolos dá-se o nome de tepe ou vibrante simples, branda ou fraca, conforme Monaretto, Quednau e Hora (2005, p. 217), como em arara, cadeira.

Em português, tanto a vibrante múltipla quanto a simples são fonemas. Ocorrem em início de sílaba (ou onset silábico) com valor contrastivo (carro (automóvel) ₹caro (dispendioso). No português de contato com falares dialetais italianos, as realizações de r-forte ou vibrante múltipla podem alternar com tepe ou vibrante simples (FROSI e MIORANZA, 1983), como em barriga bariga, arroz aroz.

Essa variação pode se verificar em diferentes municípios da antiga região colonial italiana do Rio Grande do Sul (RCI-RS) e, a exemplo de outros processos, parece caracterizar não a fala de um município, mas da região como um todo (BATTISTI e MARTINS, 2011), que compartilha traços históricos e socioculturais, além dos linguísticos.

Neste artigo, procuraremos verificar se o português falado em municípios da RCI-RS diverge ou converge no que respeita aos condicionadores sociais e linguísticos da realização variável da vibrante simples em lugar da múltipla em início de sílaba, ou onset silábico. Reuniremos, para comparação e discussão, resultados de análises sociolinguísticas dessa variável, todas fundamentadas na Teoria da Variação (LABOV, 1994, 2008 [1972]). Esse modelo de investigação tem como objeto de estudo a língua usada em comunidades de fala e preocupa-se em descrever e explicar os padrões de variação, condicionados linguística e socialmente.

Analisamos resultados de alguns estudos sobre a variação da vibrante realizados em municípios da RCI-RS. Consideramos os resultados de nosso estudo (AZEREDO, 2012) no português brasileiro de Flores da Cunha/RS em comparação aos resultados obtidos em outros dois municípios vizinhos, Antônio Prado (CORRÊA, 2016) e Caxias do Sul (BOVO, 2004). Nosso propósito, ao observar traços convergentes e divergentes no português falado em três dos municípios situados na antiga Região de Colonização Italiana no Rio Grande do Sul (RCI-RS), é verificar a possibilidade de definir a RCI-RS como uma comunidade de fala.

$\mathrm{O}$ artigo se inicia com uma breve caracterização da RCI-RS em sua história linguístico-dialetológica. A seguir conceituamos comunidade de fala, seção em que introduzimos nossas questões de estudo. Na sequência, apresentamos os resultados encontrados por Azeredo (2012) em relação à análise da regra variável, em dados de vinte informantes do município de Flores da Cunha/RS, e os comparamos aos resultados obtidos em Caxias do Sul por Bovo (2004) e em Antônio Prado por Corrêa (2016).

\section{RCI-RS: Aspectos sócio-históricos e linguísticos}

Conforme Frosi e Raso (2011), a história linguístico-dialetológica da RCI-RS entre 1875 e 1975 pode ser dividida em três períodos: o primeiro deles inicia-se em 1875 e finda em 1910; o segundo tem início em 1910 e acaba em 1950; o terceiro inicia-se em 1950 e termina em 1975. 
Segundo Frosi e Raso (2011), o primeiro período teve início com a chegada dos imigrantes italianos à RCI-RS em 1875 e foi até a inauguração da estrada de ferro que fazia ligação da RCI-RS a outras localidades, à capital do Estado e aos demais Estados da região Sul. Durante o primeiro período, a economia era definida pela policultura de subsistência. A comunicação entre as pessoas era feita nos falares dialetais italianos ${ }^{1}$ e entre indivíduos do mesmo núcleo populacional.

O segundo período, de acordo com Frosi e Raso (2011), teve início em 1910 e término em 1950. Nessa fase, estradas foram abertas ligando uma comunidade à outra das diferentes Linhas ou Travessões. O fenômeno das interinfluências dialetais assumiu uma dimensão intercomunitária. Quanto à economia, a policultura de subsistência ainda era uma característica da RCI-RS, mas o desenvolvimento do cultivo da parreira, a produção da uva e a industrialização do vinho apareciam com grande destaque. Nesse período, a língua portuguesa passou progressivamente a ganhar espaço. Foi também durante o segundo período que foi instituída a campanha de nacionalização do ensino, fazendo com que o uso da língua portuguesa fosse obrigatório.

Frosi e Raso (2011) dizem que, no terceiro período, a RCI-RS expandiu-se e cresceu economicamente. A região, conforme os autores, rompeu seu isolamento através da abertura de novas estradas e do melhoramento do sistema viário já existente. Os ítalo-descendentes alcançaram melhores condições de vida, o que fez com que sua cultura original fosse anulada em favor da vida moderna, orientada pelo modelo da sociedade brasileira.

A RCI-RS pode estar experimentando, hoje, o que Frosi e Raso (2011) entendem seja um quarto período de sua história social e linguística. Com o

\footnotetext{
${ }^{1}$ Considerando tanto a proveniência regional dos imigrantes italianos quanto as variedades por eles faladas, Frosi e Mioranza (1983, p. 110) identificam quatro grupos dialetais distintos na RCI-RS: vêneto, lombardo, friulano e trentino. Neste artigo, emprega-se o termo 'falares dialetais italianos' para referir esses grupos dialetais.
}

centenário da imigração italiana em 1975, passa-se a celebrar e reconhecer o valor da identidade italiana, ou italianidade. Os descentes dos imigrantes italianos da RCI-RS, sem deixarem de ser brasileiros, assumiram sua italianidade, sem vergonha, sem estigmas e passaram a ter orgulho das suas origens.

Como afirma Carboni (2002), esse sentimento ou orientação positiva à cultura de base étnica italiana não coincide mais com as práticas linguísticas diárias - predomina a língua portuguesa. Os falares dialetais italianos declinam e estão em vias de desaparecimento, como já observavam Frosi e Mioranza (1983, p.124). No entanto, sentimentos linguísticos italofônicos (CARBONI 2002) parecem se expressar não só na escolha de nomes italianos de pessoas e de estabelecimentos comerciais na RCI-RS, mas também sugerir que haja na região, hoje, uma certa tolerância a traços do português resultantes do contato com os falares dialetais italianos, como o emprego da vibrante simples em lugar da múltipla, antes grandemente estigmatizados (FROSI, FAGGION e DAL CORNO, 2008).

\section{Comunidade de fala}

De acordo com Labov (1994), a linguagem é concebida como um instrumento de comunicação empregado por uma comunidade de fala, um sistema comumente aceito de associações entre formas arbitrárias e seus significados. A linguagem não é entendida como uma propriedade do indivíduo, mas da comunidade.

Entende-se por comunidade de fala ou comunidade linguística um grupo de pessoas que interagem verbalmente, compartilhando um conjunto de normas de uso e avaliação linguística que distinguem seu grupo de outros, orientando seu comportamento verbal por um mesmo conjunto de regras.

Conforme Guy (2000), comunidade de fala é a unidade social usada como estrutura básica de referência para além do falante individual, entendido 
como a base em relação à qual cada idioleto é delimitado. A comunidade de fala tem duas funções na teoria sociolinguística, sendo a primeira delas fornecer uma base fundamentada capaz de explicar a distribuição social de semelhanças e diferenças linguísticas, isto é, porque alguns grupos de falantes compartilham traços linguísticos que os diferenciam de outros. A segunda função da comunidade de fala é fornecer uma justificativa teórica para unir os idioletos de falantes individuais às línguas.

Segundo Labov (2010), o dogma central da sociolinguística é que a comunidade é prévia ao indivíduo. Isso significa que, na análise linguística, o comportamento do indivíduo pode ser entendido somente através do grupo social do qual ele é membro.

Ao estudar a palatização variável de /t/ e /d/ (tia tfia, dia dzia) no português falado em municípios da antiga região colonial italiana do Rio Grande do Sul, Battisti (2011) necessitou discutir o conceito de comunidade de fala e retomar o problema da implementação levantado por Weinreich, Labov e Herzog (2006 [1968]). A esses autores intriga o fato de apesar dos mesmos condicionamentos estruturais, um mesmo processo ser implementado e ter aplicação conforme padrões distintos em diferentes comunidades de fala de uma mesma língua (divergência dialetal, de acordo com Labov 2010). Na via inversa, conforme Battisti (2011), um mesmo processo, como o da palatalização de /t/ e /d/, que poderia apresentar padrão de aplicação distinto em comunidades de fala diferentes (em tamanho da população, pelo menos) é efeito basicamente dos mesmos condicionamentos sociais e linguísticos (convergência dialetal).

A hipótese de Weinreich, Labov e Herzog (2006 [1968]) é a de que [a variação] e mudança linguística é mudança no comportamento social. Comunidades geograficamente vizinhas poderiam, então, exibir padrões de variação linguística distintos se sua sócio-história e estruturação econômico-cultural viesse a diferenciar-se. Ou, opostamente, se essas condições históricas, sociais, culturais e econômicas vierem a se assemelhar, exibir comportamentos semelhantes na aplicação de processos variáveis, desfazendo os limites geopolíticos de suas comunidades e sendo integradas numa só. É o que defende Battisti (2011) para a RCI-RS no que se refere à palatalização. Os três municípios por ela investigados - Caxias do Sul, Antônio Prado e Flores da Cunha -, apesar de distintos no tamanho da população ${ }^{2} \mathrm{e}$ na estruturação urbana e econômica, exibem praticamente o mesmo padrão de palatalização. Pergunta-se no presente estudo: em relação ao emprego variável de vibrante simples em lugar de múltipla, esses três municípios exibem o mesmo padrão? Confirma-se a hipótese de Battisti (2011) de que a RCI-RS, não os municípios isoladamente, seja a comunidade de fala relevante na análise de processos variáveis no português falado a nordeste do Rio Grande do Sul?

As três cidades da antiga RCI-RS - Antônio Prado, Caxias do Sul e Flores da Cunha - têm origem ética predominantemente italiana. Citamos Zanini (2006), que estudou a italianidade na região de Santa Maria (RS). Segundo a autora, os ítalo-descendentes da região fazem com que a etnia seja transformada em um código capaz de revelar diferenças quanto a estilo de vida, posições sociais e poder, o que se verifica também na forma de expressão, expressão essa que disputa prestígio com as linguagens oficiais. Zanini (2006) acredita que, agindo desta maneira, os descentes de italianos residentes na região de Santa Maria sentem-se parte de uma comunidade imaginada. Battisti (2011) acredita que os descendentes de italianos da RCI-RS expressam essa mesma italianidade e participam, também, de uma comunidade imaginada, o que sustentaria a hipótese analítica de tomar a RCI-RS em seu todo como uma comunidade de fala.

2 Conforme informações disponibilizadas pelo IBGE (http://www.cidades.ibge.gov.br/, acesso em 04/05/2016), a população estimada de Antônio Prado em 2015 é de 13.285 habitantes, a de Flores da Cunha, 29.196 habitantes, a de Caxias do Sul, 474.853 habitantes. 
Figura 1 - Mapa parcial do Rio Grande do Sul com a localização de Antônio Prado, Caxias do Sul e Flores da Cunha

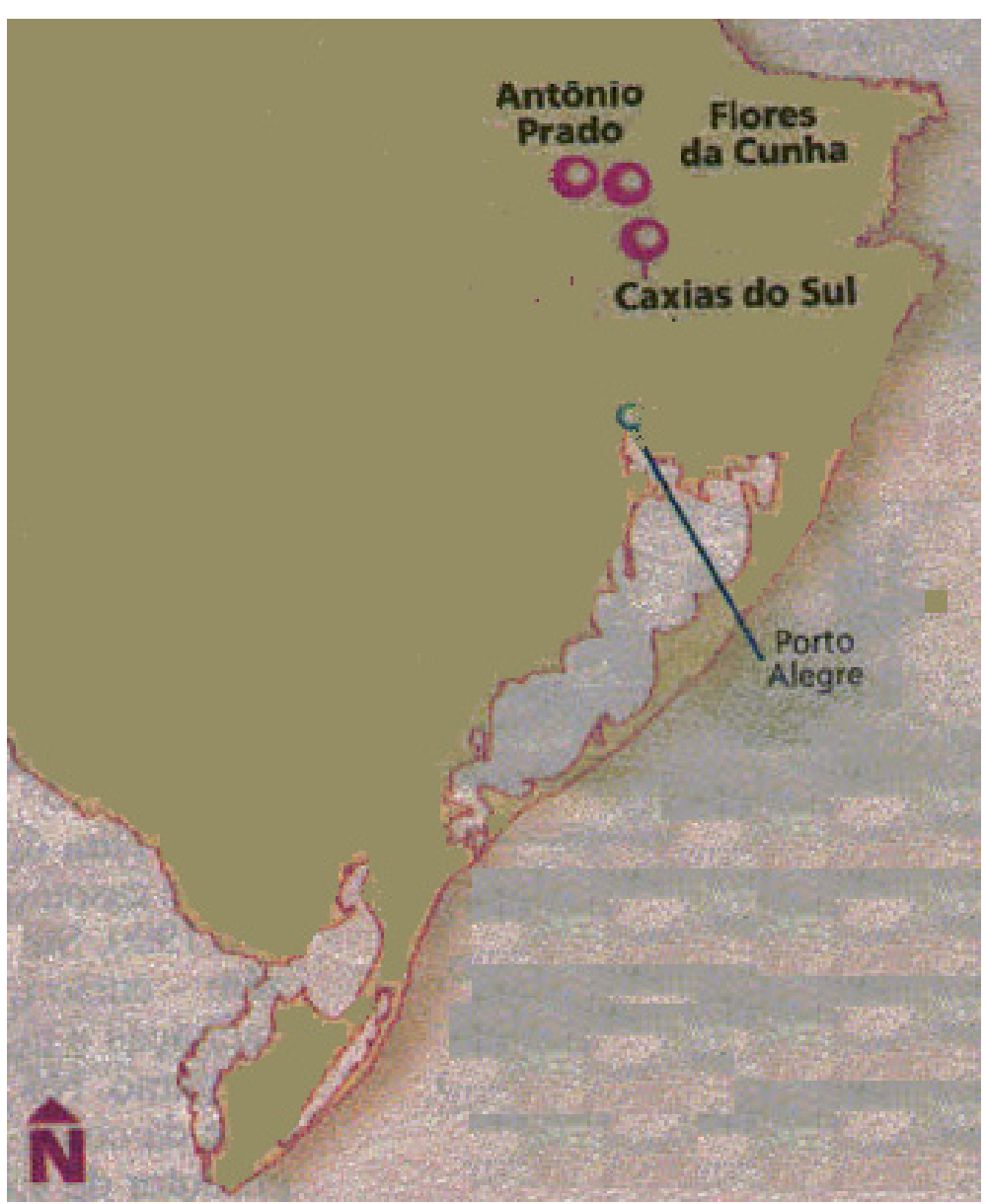

De acordo com Battisti (2011), no que se refere à italianidade do ítalo-brasileiro e seus reflexos na língua: $A$ origem familiar e seus símbolos, entre eles os linguísticos, convertem-se em patrimônio, em capital cultural que compete no mercado de bens simbólicos locais, regionais e nacionais, e contribui para a distinção simbólica e visibilidade do grupo. O fato de os traços do contato serem mantidos ou não no português falado na comunidade está diretamente associado à ideia de patrimônio cultural, podendo este ser valorizado ou desprestigiado.

\section{A realização da vibrante simples em lugar de múltipla em Flores da Cunha}

O ponto de partida da análise de convergência e divergência dos grupos de fatores condicionadores da realização de vibrantes simples em lugar de múltipla no português falado em três municípios da RCI-RS - Flores da Cunha, Caxias do Sul, Antônio Prado - serão, respectivamente, os resultados de nosso estudo (AZEREDO, 2012), os de Bovo (2004) e os de Corrêa (2016). As entrevistas sociolinguísticas de que se levantaram os dados analisados pertencem ao mesmo acervo, o BDSer (Banco de Dados de Fala da Serra Gaúcha, UCS). No entanto, foram realizadas em períodos distintos: as entrevistas de Caxias do Sul, entre 2000 e 2002, as de Antônio Prado, entre 2005 e 2006, as de Flores da Cunha, entre 2008 e 2009.

Em nossa pesquisa (AZEREDO, 2012), usamos dados levantados de vinte entrevistas sociolinguísticas.

As variáveis extralinguísticas controladas na pesquisa foram: gênero, idade, escolaridade e bilinguismo. Os informantes são dos dois gêneros masculino e feminino, pertencem a três grupos etários ( 25 a 39 anos, 45 a 59 anos e 60 ou mais anos), sua escolaridade varia entre Ensino Fundamental e Ensino Médio e podem ser bilíngues ativos (além da língua portuguesa, falam e entendem falares dialetais italianos) ou passivos (só entendem falares dialetais italianos, mas não os falam). Quanto às variáveis linguísticas, foram controladas: tonicidade (sílaba tônica 'roupa', sílaba átona 'retoque'), 
posição da sílaba na palavra (inicial 'rua', medial 'churrasco') e número de sílabas da palavra (monossílabo 'réu', dissílabo 'carro', trissílabo 'carroça', polissílabo 'retangular').

Para a análise da regra variável, foram levantados 1.440 contextos de vibrante. Tais dados foram codificados e submetidos ao pacote de programas VARBRUL (Goldvarb X). Das sete variáveis controladas, seis foram selecionados como relevantes para aplicação da regra pelo programa. Apresentaremos os resultados dos grupos selecionados por ordem de relevância estatística: Bilinguismo, Idade, Escolaridade, Posição da sílaba na palavra, Gênero e Número de sílabas na palavra - e os compararemos aos obtidos por Bovo (2004) para Caxias do Sul e Corrêa (2016) para Antônio Prado.

O grupo de fatores que se mostrou mais forte condicionador de aplicação da regra em Flores da Cunha (AZEREDO, 2012) foi a variável Bilinguismo. Quanto mais uso o informante faz do dialeto italiano, maior é a probabilidade de usar o tepe em lugar de vibrante (peso relativo de 0,71 no fator Ativo, ver Tabela 1).

Tabela 1 - Bilinguismo

\begin{tabular}{lccc}
\hline Fatores & Aplicação/Total & $\%$ & Peso Relativo \\
\hline Ativo (fala e entende) & $423 / 1090$ & 39 & 0.71 \\
Passivo (só entende) & $20 / 350$ & 6 & 0.06 \\
Total & $443 / 1440$ & 31 & \\
\hline
\end{tabular}

Input: 0,391; significância: 0,001.

Ao fazermos a comparação (proporções de aplicação) entre os municípios, observamos que, tanto em Caxias do Sul quanto em Flores da Cunha, os informantes bilíngues ativos são os condicionadores da regra variável em questão como nos mostra o gráfico a seguir. Na pesquisa feita em Antônio Prado, a autora não controlou a variável bilinguismo.
Gráfico 1 - Proporção de realização da vibrante simples em lugar da múltipla para a variável Bilinguismo em Flores da Cunha e Caxias do Sul

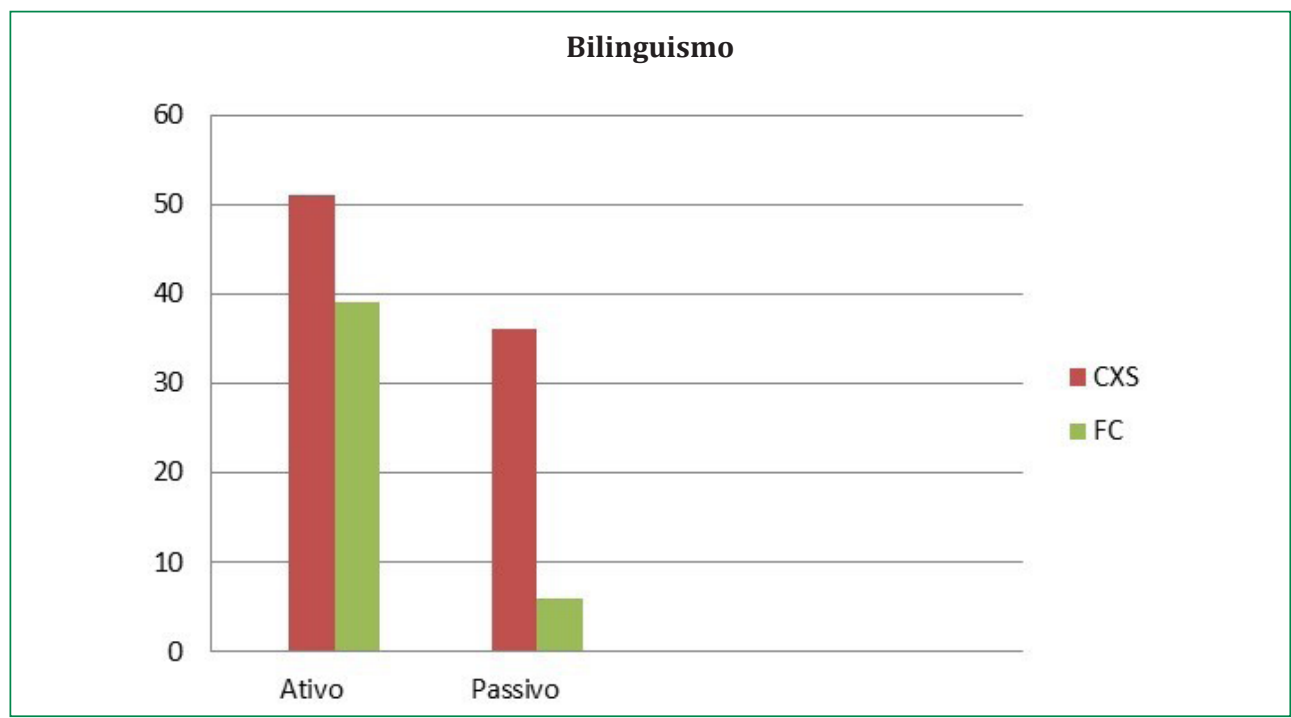

O grupo de fatores Idade, segundo selecionado pelo programa de análise de dados, parece indicar mudança em progresso na cidade de Flores da Cunha: tanto o grupo etário mais jovem quanto o intermediário favorecem a realização de vibrante simples em lugar de múltipla como mostra a Tabela 2 que apresenta pesos relativos 0,72 e 0,65, respectivamente.

Tabela 2 - Idade

\begin{tabular}{lccc}
\hline Fatores & Aplicação/Total & $\%$ & Peso Relativo \\
25 a 39 anos & $162 / 458$ & 35 & 0.72 \\
40 a 59 anos & $120 / 339$ & 35 & 0.65 \\
60 ou + anos & $161 / 643$ & 25 & 0.26 \\
Total & $443 / 1440$ & 31 & \\
\hline
\end{tabular}

Input: 0,391; significância: 0,001. 
Por acreditarmos que os mais jovens têm um contato maior com a língua portuguesa em suas práticas sociais, nossa hipótese inicial era a de que, quanto maior fosse a idade do informante, maior seria a aplicação da regra variável, isto é, os mais velhos produziriam mais tepe em contextos em que se espera a vibrante, mas como podemos observar, nossa hipótese inicial foi contrariada.

Segundo Battisti e Martins (2011), ao se observarem as práticas sociais de jovens florenses mais sistematicamente, ao serem considerados os assuntos de que falam e as questões sobre que debatem, percebe-se um localismo peculiar, o que os diferencia dos demais jovens gaúchos. Segundo as autoras, esse localismo pode explicar as vinculações das práticas destes jovens com as tradições da imigração italiana, talvez reforçadas pelas festas locais e pelo turismo. Isso pode explicar os resultados estatísticos para a variável Idade em nosso estudo.

Em Azeredo (2012), fizemos algumas adaptações quanto à variável faixa etária para realizar análise em tempo real ${ }^{3}$. Para isso, utilizou-se além do BDSer (2008-2009) o Banco Varsul (1990). Em decorrência disso, as faixas etárias dos informantes não correspondem exatamente à estratificação de cada um dos bancos considerados. Buscou-se homogeneizar as idades para fins de nosso estudo, o que exigiu recorrer às informações pontuais registradas nas Fichas Sociais dos informantes para desenhar os grupos etários.

Ao fazermos a comparação com os estudos realizados em Caxias do Sul e Antônio Prado, em que o banco de dados utilizado na pesquisa foi somente o BDSer, observamos que a variável Idade foi estratificada da seguinte maneira: Caxias do Sul: 15 a 25 anos; 26 a 49 anos e 50 ou mais anos. Antônio

3 Análises variacionistas (LABOV, 1994) em tempo real utilizam duas amostras de fala, coletadas em períodos de tempo distintos dos mesmos informantes ou de informantes de perfil social similar.
Prado: 15 a 30 anos; 31 a 50anos; 51 a 70 anos e 71 ou mais anos, o que de certa forma dificultou a comparação de dados e nos impossibilitou de fazer um gráfico comparativo para a variável idade. Apresentamos no Gráfico 2, os resultados de Bovo (2004) e Corrêa (2016) para Caxias do Sul (CXS) e Antônio Prado (AP), respectivamente.

Gráfico 2 - Proporção de realização da vibrante simples em lugar da múltipla para a variável Idade em Antônio Prado e Caxias do Sul

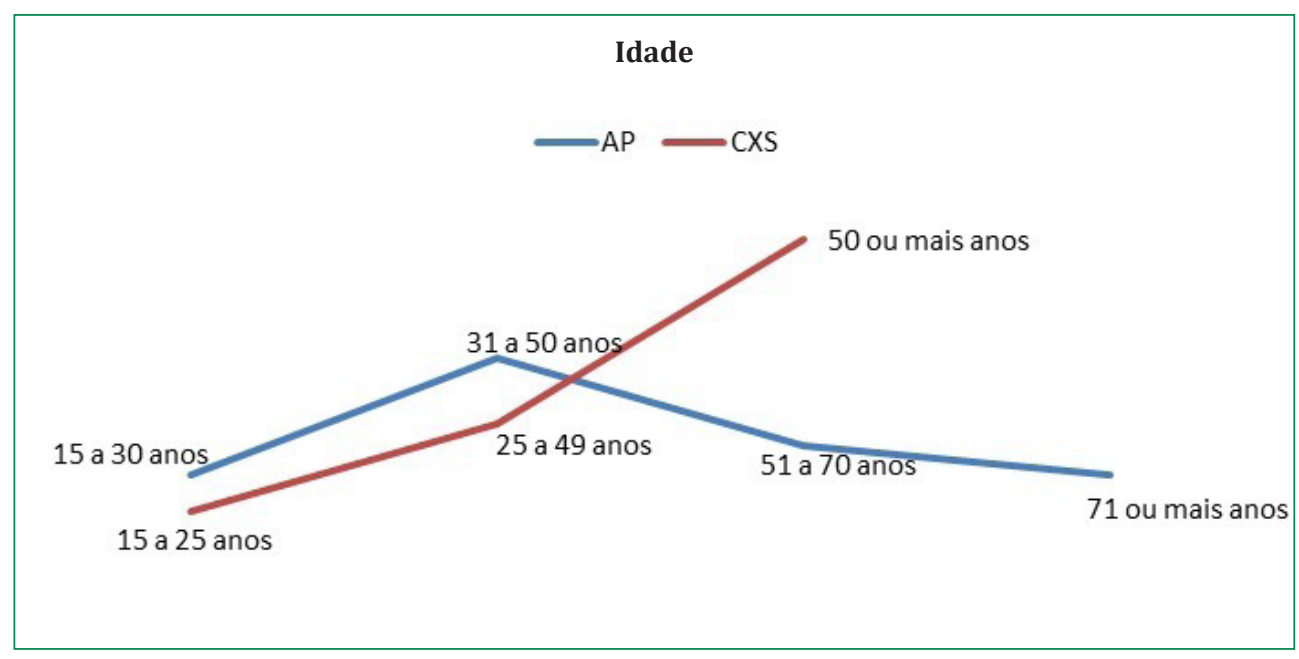

Bovo (2004) constatou que são os mais velhos os favorecedores do uso do tepe em Caxias do Sul. A faixa etária com 50 anos ou mais apresentou um peso relativo de 0,70 e confirmou a hipótese inicial da autora de que, quanto maior a idade, maior a aplicação da regra variável, visto que os mais jovens têm mais contato com a língua portuguesa através dos meios de comunicação e participam mais de atividades sociais fora da comunidade.

Opostamente, Corrêa (2016) verificou que, em Antônio Prado, a Faixa Etária 31 a 50 anos favorece a aplicação de vibrante simples, enquanto as 
outras faixas desfavorecem. Como Azeredo (2012), a autora não confirmou a hipótese de que os informantes de idade mais avançada favoreceriam a aplicação da regra.

O terceiro grupo selecionado na nossa pesquisa foi o grupo Escolaridade. Dividimos esse grupo em duas categorias: Ensino Fundamental e Ensino Médio. Como nos mostra a Tabela 3, o grupo com menor escolaridade é o favorecedor da regra.

Tabela 3 - Escolaridade

\begin{tabular}{lccc}
\hline Fatores & Aplicação/Total & \% & Peso Relativo \\
Ensino Fundamental & $305 / 752$ & 41 & 0.70 \\
Ensino Médio & $138 / 688$ & 20 & 0.29 \\
Total & $443 / 1440$ & 31 & \\
\hline
\end{tabular}

Input: 0,391; significância: 0,001.

Com estes resultados, pudemos concluir que, quanto maior a escolaridade, menor é o emprego de tepe em contexto em que se espera a vibrante, ou seja, quanto maior a exposição ao padrão fonológico do português, maior a consciência do falante sobre a correção em seu modo de falar e maior é a probabilidade de reproduzir as normas linguísticas. Observamos o mesmo resultado nos estudos feitos por Bovo (2004) e Corrêa (2016) em Caxias do Sul e em Antônio Prado, respectivamente (Gráfico 3).

Bovo (2004) verificou que, em Caxias do Sul, quem concluiu o Ensino Fundamental e foi adiante em seus estudos não favoreceu a aplicação da regra. A autora dividiu seus informantes em Fundamental, Primário e Médio/ Superior. Consideramos para nossa pesquisa somente os níveis Ensino Fundamental e Ensino Médio/Superior.

Corrêa (2016) diz que os níveis mais altos de escolaridade apresentam frequência bem menor de realização da vibrante simples em lugar de múltipla em Antônio Prado. A autora dividiu seus informantes em Primário/ Fundamental e Médio/Superior.

Gráfico 3 - Proporção de realização da vibrante simples em lugar da múltipla para a Variável Escolaridade em Antônio Prado, Caxias do Sul e Flores da Cunha

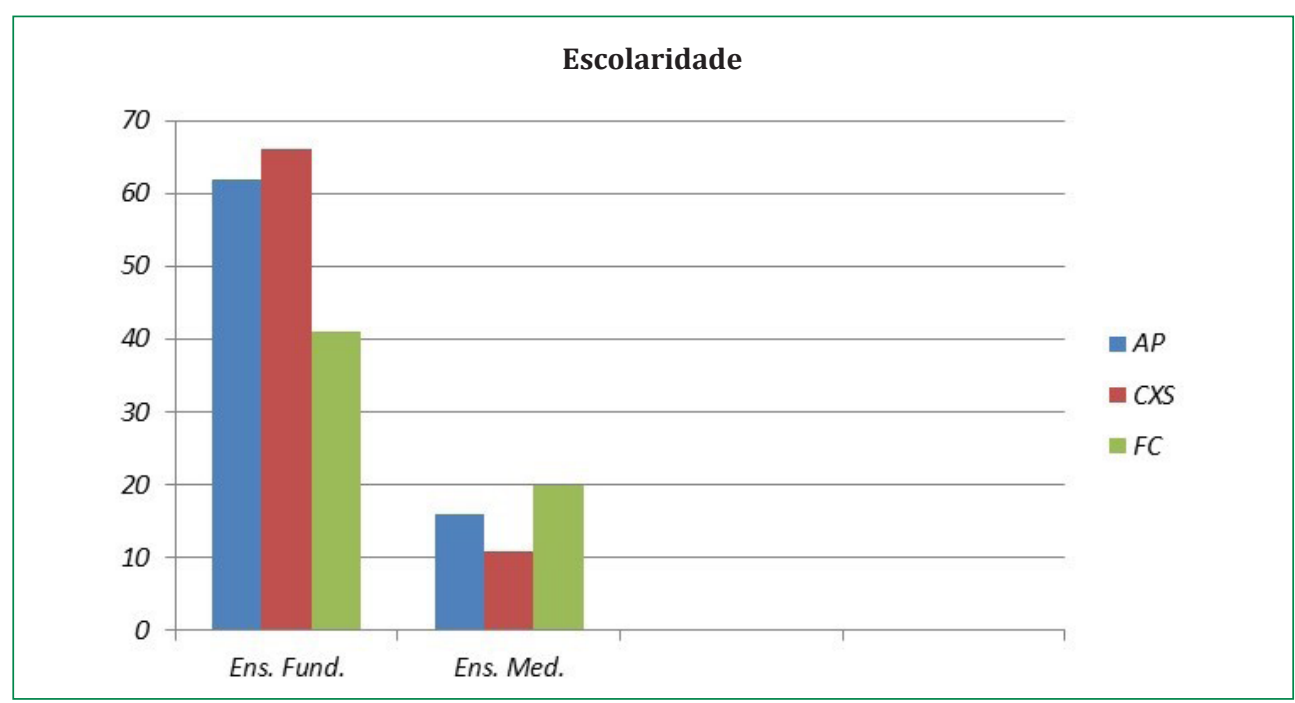

A quarta variável selecionada pelo programa foi a Posição da Sílaba na Palavra. Constatamos em nossa pesquisa que o fator Sílaba Medial é o favorecedor da regra variável (peso relativo de 0,62, cf. Tabela 4).

Tabela 4 - Posição da Sílaba na Palavra

\begin{tabular}{lccc}
\hline Fatores & Aplicação/Total & \% & Peso Relativo \\
Medial - terra & $211 / 532$ & 40 & 0.62 \\
Inicial -roda & $232 / 908$ & 26 & 0.43 \\
Total & $443 / 1440$ & 31 & \\
\hline
\end{tabular}

Input 0,391; significância 0,001; 
Os resultados estatísticos para este fator confirmam a hipótese de que, quando a consoante ocupa a posição medial da palavra, há o favorecimento da aplicação da regra variável, neste caso, tepe em lugar de vibrante. Isso talvez se deva ao fato de, nessa posição, a consoante em início de sílaba não ser tão saliente quanto no início da palavra. Com esse resultado, pudemos chegar à conclusão de que as bordas da palavra não são favorecedoras de aplicação da regra variável em questão, o que está de acordo com o verificado por Bovo (2004) em Caxias do Sul (Gráfico 4). Já em Antônio Prado, Corrêa (2016) nos mostra que os pesos relativos para a variável Posição da Sílaba na palavra giram em torno do ponto neutro. Ao fazer o cruzamento dos dados, a autora verificou que a posição medial só apresenta maior frequência em vocábulos polissílabos, como beterraba e carrancudo.

Gráfico 4 - Proporção de realização da vibrante simples em lugar da múltipla para a Variável Posição da Sílaba na Palavra em Antônio Prado, Caxias do Sul e Flores da Cunha

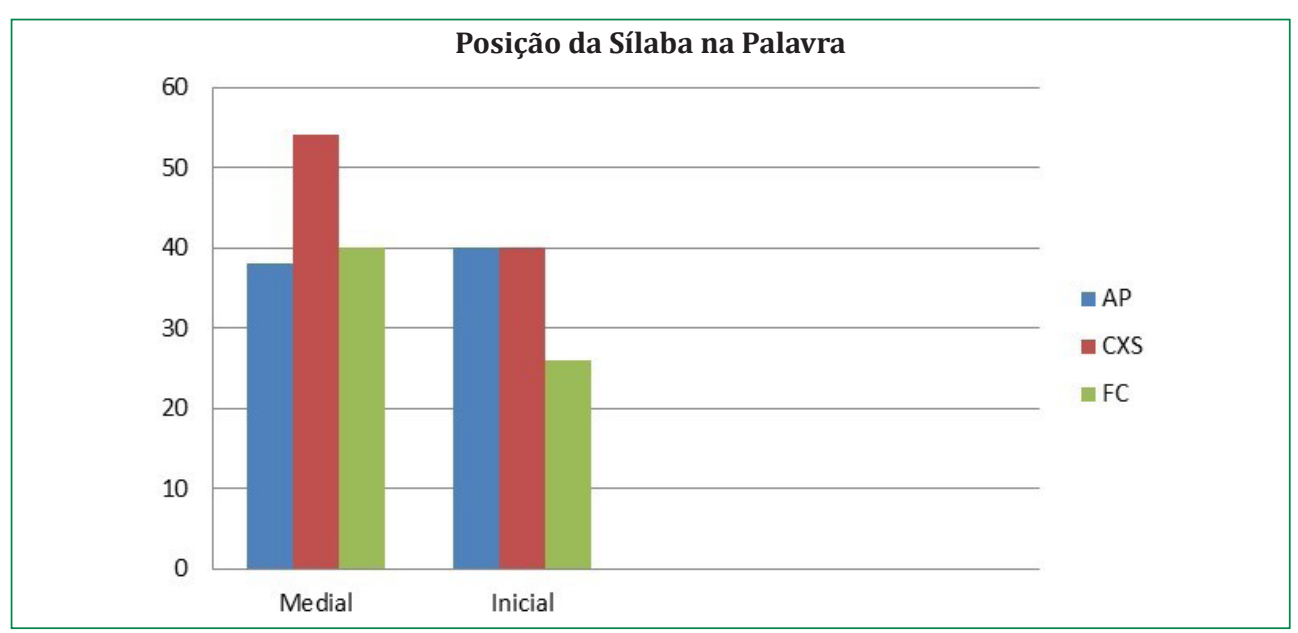

A quinta variável selecionada pelo programa foi a variável Gênero. Percebemos que em Flores da Cunha os homens empregam mais o tepe do que as mulheres, favorecendo a aplicação da regra (peso relativo de 0,55, cf. Tabela 5).

Tabela 5 - Gênero

\begin{tabular}{lccc}
\hline \multicolumn{1}{r}{ Fatores } & Aplicação/Total & $\%$ & Peso Relativo \\
Masculino & $292 / 748$ & 39 & 0.55 \\
Feminino & $151 / 692$ & 22 & 0.44 \\
Total & $443 / 1440$ & 31 & \\
\hline
\end{tabular}

Input: 0,391; significância: 0,001.

Tal resultado também foi observado em Caxias do Sul por Bovo (2004) e em Antônio Prado por Corrêa (2016) (Gráfico 5), o que vai ao encontro da afirmação de Labov (2008 [1972]), que diz que as mulheres são mais sensíveis ao uso das formas de prestígio, mostrando-se mais inovadoras no uso de uma regra apenas quando não se trata de uma forma estigmatizada.

Gráfico 5 - Proporção de realização da vibrante simples em lugar da múltipla para a Variável Gênero em Antônio Prado, Caxias do Sul e Flores da Cunha

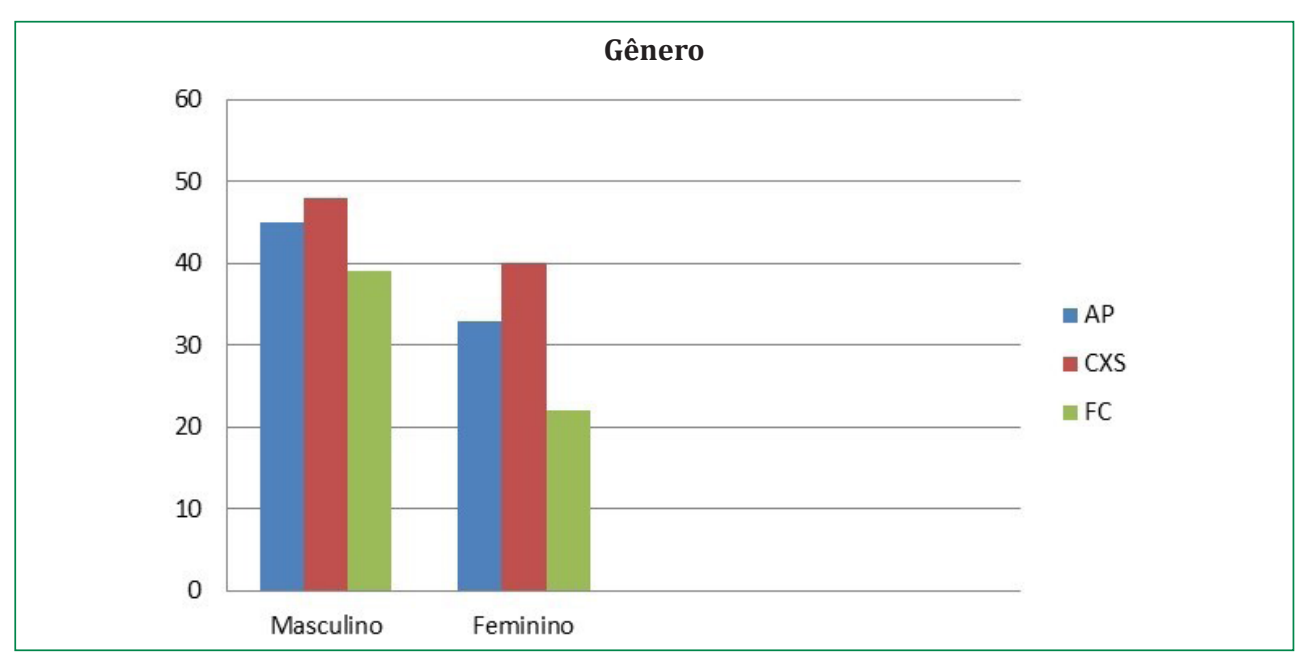


A sexta e última variável selecionada pelo programa foi Número de sílabas. Conforme apresentado na Tabela 6, são as palavras trissílabas que condicionam a aplicação da regra, contrariando as nossas hipóteses iniciais, de que quanto maior a palavra, maior seria a chance de se produzir tepe em contexto em que se espera a vibrante.

Tabela 6 - Número de Sílabas

\begin{tabular}{lccc}
\hline Fatores & Aplicação/Total & \% & Peso Relativo \\
Polissílaba - Rigoroso & $67 / 265$ & 25 & 0.46 \\
Dissílaba - Raro & $178 / 594$ & 30 & 0.45 \\
Trissílaba - Terreno & $198 / 581$ & 34 & 0.57 \\
Total & $443 / 1440$ & 31 & \\
\hline
\end{tabular}

Input: 0,391; Significância: 0,001.

\section{Gráfico 6}

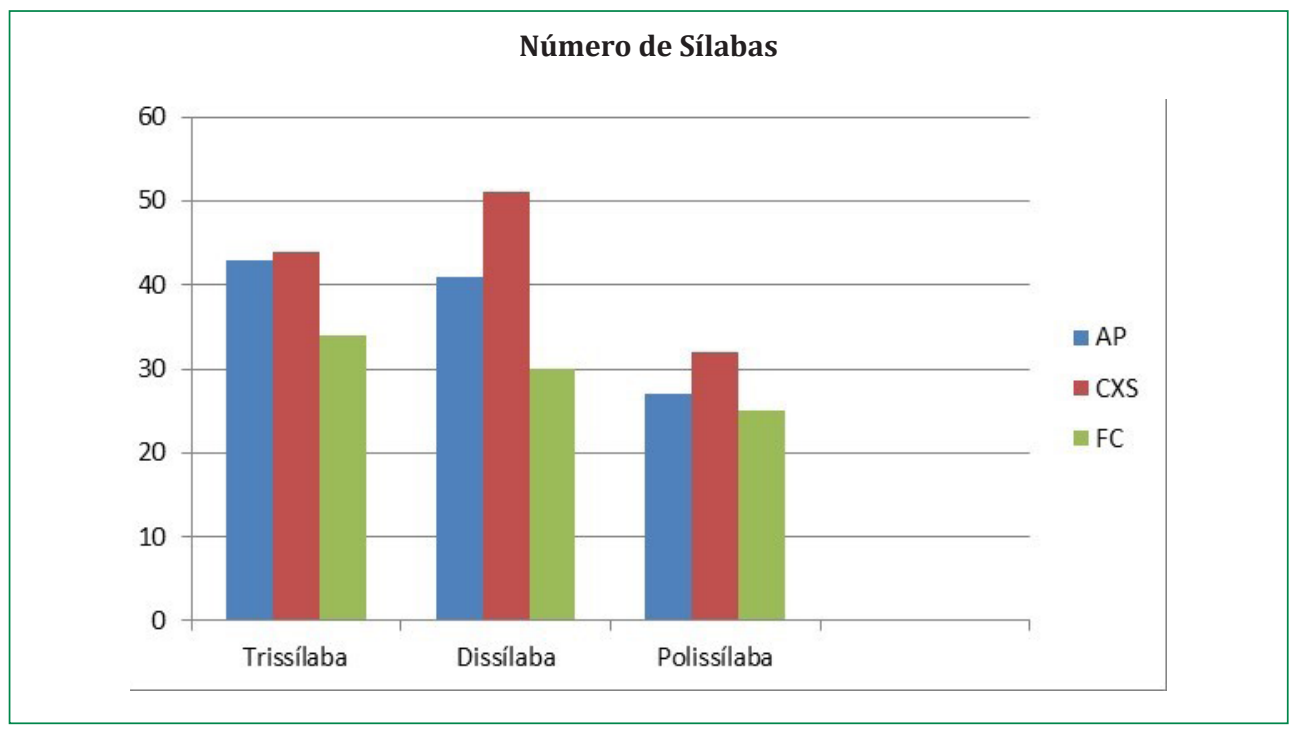

Corrêa (2016) observou que as palavras polissílabas desfavorecem a regra em Antônio Prado, pois apresentam um peso relativo de apenas 0,40 . A autora também verificou que palavras trissílabas, monossílabas e dissílabas giram em torno do ponto neutro em relação ao peso relativo.

Com os dados de Caxias do Sul, Bovo (2004) precisou amalgamar os fatores monossílabos com os dissílabos devido à baixa ocorrência de vocábulos monossílabos, optando por eliminá-los de sua amostra. Como consequência, o programa não selecionou a variável entre as que condicionam a aplicação da regra porque os valores dos pesos relativos giraram em torno do ponto neutro (Gráfico 6).

\section{Conclusão}

O exame dos resultados de nossa análise (AZEREDO, 2012) da realização variável de vibrante simples em lugar de múltipla no português falado em Flores da Cunha, município da RCI-RS, em comparação aos de Bovo (2004) para Caxias do Sul e de Corrêa (2016) para Antônio Prado, revelaram tanto convergências quanto divergências dialetais no que tange aos fatores condicionadores do processo variável.

Pelos resultados obtidos nas três pesquisas, pode-se afirmar que as variáveis linguísticas não desempenham forte condicionamento sobre a regra variável de realização do tepe em lugar de vibrante nas cidades em estudo. 0 mais forte condicionamento vem das variáveis sociais. Em Azeredo (2012), por exemplo, das seis variáveis selecionadas pelo programa, quatro são extralinguísticas. Esse aspecto parece ser regional. Quanto aos fatores condicionadores de cada variável linguística, observamos resultados semelhantes em Flores da Cunha e Caxias do Sul na variável Posição da Sílaba na Palavra: quando a consoante ocupa a posição medial há o favorecimento 
da aplicação da regra variável. Em Antônio Prado, Corrêa (2016) observou esse resultado nas palavras polissílabas.

Algumas das variáveis extralinguísticas são condicionadoras da regra variável nos três municípios, tais como escolaridade e gênero, nos fatores referentes aos mais baixos níveis de escolaridade e a masculino. A variável Bilinguismo, controlada apenas em duas das três análises, também se mostrou forte condicionador da regra variável: favorecem o emprego de tepe em lugar de vibrante os bilíngues ativos. Porém, os resultados da variável Idade foram diferentes para os grupos etários considerados na análise de cada uma das cidades estudadas: em Caxias do Sul, o grupo etário mais idoso tende a aplicar a regra; em Antônio Prado, o grupo etário intermediário, em Flores da Cunha, os grupos etários mais jovens. Esses resultados divergentes não permitem tecer generalizações, tampouco fazer afirmações sobre o progresso ou regressão dessa realização no todo das comunidades da RCI-RS. Exige considerar aspectos pontuais da sócio-história e cultura locais de cada comunidade para compreender os padrões etários. Isso, por sua vez, não permite confirmar nossa hipótese de fundo, de que se poderia considerar, para fins analíticos, a RCI-RS como uma comunidade de fala.

$\mathrm{O}$ conjunto de resultados referentes à realização variável de vibrante simples em lugar de múltipla em municípios da RCI-RS, nos três estudos examinados, aproxima Caxias do Sul e Flores da Cunha, e distingue Antônio Prado. Essa comunidade já havia apresentado divergência quando, no estudo da palatalização variável de /t/ e /d/, o grupo etário mais jovem não apresentou incremento na aplicação da regra, fato esse que se verifica em Caxias do Sul e Flores da Cunha (BATTISTI, 2011).

Nosso estudo confirma apenas parcialmente a hipótese de que a RCI-RS fosse a comunidade de fala relevante para a análise da realização variável da vibrante simples em lugar da múltipla. Nosso estudo mostrou que, a despeito de muitas similaridades e da italianidade compartilhada, as realidades locais, coincidentes com os limites municipais, precisam ser contempladas na análise desse processo variável em específico.

\section{Referências}

AZEREDO, Priscila Silvano. A troca da vibrante por tepe em onset silábico: uma análise de variação e mudança linguística na comunidade bilíngue de Flores da Cunha/RS Dissertação (Mestrado em Letras) - Instituto de Letras, Programa de Pós-Graduação em Letras, Universidade Federal do Rio Grande do Sul, Porto Alegre, 2012.

BATTISTI, Elisa; MARTINS, Luisa Bitencourt. A realização da variável vibrante simples em lugar de múltipla no português falado em Flores da Cunha (RS): Mudanças sociais e linguísticas. In: Caderno do IL, v. 42, 2011, n. 1- 2, ISSN 0104-1886.

BOVO, Nínive Magdiel Peter. A variação da vibrante e seu valor social. Dissertação (Mestrado e Letras e Cultura Regional) - Programa de Pós-Graduação em Letras e Cultura Regional, Universidade de Caxias do Sul, Caxias do Sul, 2004.

CARBONI, Florence. "Eppur si parlano": etude diachronique d'um cas de contact linguistique dans le Rio Grande do Sul (Brésil). Passo Fundo: UPF Editora, 2002.

CORRÊA, Raquel da Costa. A realização variável de vibrante simples em lugar de múltipla em onset silábico no português falado em Antônio Prado-RS. Dissertação (Mestrado em Letras) - Instituto de Letras, Programa de Pós-Graduação em Letras, Universidade Federal do Rio Grande do Sul, Porto Alegre, 2016.

FROSI, Vitalina Maria; FAGGION, Carmen; DAL CORNO, Giselle Olívia Mantovani. Prestígio e estigmatização: dialeto italiano e língua portuguesa da região de colonização italiana do nordeste do Rio Grande do Sul. Revista da ABRALIN, v. 7, n. 2, p. 139-167, jul./dez. 2008.

FROSI, Vitalina Maria; MIORANZA, Ciro. Dialetos italianos: um perfil linguístico dos ítalobrasileiros do Nordeste do Rio Grande do Sul. Caxias do Sul: EDUCS, 1983.

FROSI, Vitalina Maria; RASO, Tommaso. O italiano no Brasil: Um caso de contato linguístico e cultural. In: MELLO, H.; ALTENHOFEN, C. V.; RASO, T. (Org.). Os contatos linguísticos no Brasil. Belo Horizonte: Editora UFMG, 2011. p. 317-347.

GUY, G. R. A identidade linguística da comunidade de fala: paralelismo interdialetal nos padrões de variação linguística. Organon, v. 14, n. 28-29, 2000. 
LABOV, William. Principles of linguistic change. Volume 1: Internal factors. Oxford: Blackwell, 1994.

Principles of linguistic change: Social factors. Oxford: Blackwell, 2001.

Padrões sociolinguísticos. São Paulo: Parábola, 2008 [1972].

Principles of linguistic change. Volume 3: Cognitive and Cultural Factors. Oxford: Blackwell, 2010.

MONARETTO, Valéria N. O. Um reestudo da vibrante: análise variacionista e fonológica. Tese (Doutorado em Letras) - Pontifícia Universidade Católica do Rio Grande do Sul, Porto Alegre, 1997.

MONARETTO, Valéria N. O.; QUEDNAU, Laura Rosane; HORA, Demerval da. As consoantes do português. In: BISOL, Leda (Org.). Introdução a estudos de fonologia do português brasileiro. 4. ed. rev. ampl. Porto Alegre: EDIPUCRS, 2005. p. 207-241.

WEINREICH, Uriel; LABOV, William; HERZOG, Marvin I. Fundamentos empíricos para uma mudança linguística. Tradução de Marcos Bagno. São Paulo: Parábola, 2006 [1968].

ZANINI, M.C.C Italianidade no Brasil meridional: a construção da identidade étnica na região de Santa Maria-RS. Santa Maria: Editora da UFSM, 2006.

Recebido em 28/08/2016.

Aceito em 24/01/2017. 